\title{
Article \\ High Glucose-Induced Apoptosis Is Linked to Mitochondrial Connexin 43 Level in RRECs: Implications for Diabetic Retinopathy
}

\author{
Aravind Sankaramoorthy ${ }^{1}$ and Sayon Roy ${ }^{1,2, *}$ \\ 1 Department of Medicine, Boston University School of Medicine, Boston, MA 02118, USA; asankara@bu.edu \\ 2 Department of Ophthalmology, Boston University School of Medicine, Boston, MA 02118, USA \\ * Correspondence: sayon@bu.edu; Tel.: +1-(617)-358-6801; Fax: +1-(617)-638-4177
}

Citation: Sankaramoorthy, A.; Roy, S High Glucose-Induced Apoptosis Is Linked to Mitochondrial Connexin 43 Level in RRECs: Implications for Diabetic Retinopathy. Cells 2021, 10, 3102. https://doi.org/10.3390/ cells10113102

Academic Editor: Alexander E. Kalyuzhny

Received: 13 October 2021 Accepted: 5 November 2021 Published: 10 November 2021

Publisher's Note: MDPI stays neutral with regard to jurisdictional claims in published maps and institutional affiliations.

Copyright: (C) 2021 by the authors. Licensee MDPI, Basel, Switzerland. This article is an open access article distributed under the terms and conditions of the Creative Commons Attribution (CC BY) license (https:// creativecommons.org/licenses/by/ $4.0 /)$.

\begin{abstract}
Diabetic retinopathy (DR) is one of the most common causes of vision loss and blindness among the working-age population. High glucose (HG)-induced decrease in mitochondrial connexin 43 (mtCx43) level is known to promote mitochondrial fragmentation, cytochrome c release, and apoptosis in retinal endothelial cells associated with DR. In this study, we investigated whether counteracting HG-induced decrease in $\mathrm{mtCx} 43$ level would preserve mitochondrial integrity and prevent apoptosis. Rat retinal endothelial cells (RRECs) were grown in normal (N; $5 \mathrm{mM}$ glucose) or HG (30 mM glucose) medium for 7 days. In parallel, cells grown in HG were transfected with Cx43 plasmid, or empty vector (EV), as control. Western blot (WB) analysis showed a significant decrease in $\mathrm{mtCx} 43$ level concomitant with increased cleaved caspase-3, Bax, cleaved PARP, and mitochondrial fragmentation in cells grown in $\mathrm{HG}$ condition compared to those grown in $\mathrm{N}$ medium. When cells grown in HG were transfected with Cx43 plasmid, mtCx43 level was significantly increased and resulted in reduced cleaved caspase-3, Bax, cleaved PARP and preservation of mitochondrial morphology with a significant decrease in the number of TUNEL-positive cells compared to those grown in $\mathrm{HG}$ alone. Findings from the study indicate a novel role for $\mathrm{mtCx} 43$ in regulating apoptosis and that maintenance of $\mathrm{mtCx} 43$ level could be useful in preventing HG-induced apoptosis by reducing mitochondrial fragmentation associated with retinal vascular cell loss in DR.
\end{abstract}

Keywords: high glucose; apoptosis; mitochondrial connexin 43; endothelial cells; diabetic retinopathy

\section{Introduction}

Diabetic retinopathy is a long-term microvascular complication of diabetes. As the diabetic population keeps increasing, the prevalence of DR keeps surging and is estimated at 103 million globally [1]. The Diabetes Control and Complications Trial and the UK Prospective Diabetes Study among others have well-established hyperglycemia to be a major factor in promoting microvascular complications including DR [2]. A prominent early-stage lesion of DR is apoptotic cell loss in the retinal vasculature [3-7]. Since mitochondria and $\mathrm{Cx} 43$ are key players in regulating apoptosis, in this study, we investigated the effects of $\mathrm{HG}$ on mtCx43 level and how it may impact the development of retinal vascular cell loss in the early stages of DR.

Evidence indicates that $\mathrm{mtC} 43$ plays a critical role in regulating mitochondrial function [8-10] and apoptosis mediated through the mitochondrial intrinsic pathway via release of cytochrome c [11-13] and initiation of caspase-3 dependent cascade [14]. Several studies have reported the presence of Cx43 in the inner mitochondrial membrane (IMM) [10,15-19], however, their exact function is unclear. Previously we have observed that HG downregulates mtCx43 level concomitant with increased mitochondrial fragmentation and apoptosis in retinal endothelial cells [10]. However, it is unknown whether counteracting the HGinduced decrease in $\mathrm{mtC} \times 43$ level would be beneficial against HG-induced apoptosis in retinal endothelial cells. 
Presence of $\mathrm{Cx} 43$ in mitochondria has unveiled certain noncanonical biological processes [20-22]. Previously we have shown that downregulation of Cx43 using siRNA in retinal endothelial cells [23] decreases gap junction intercellular communication (GJIC), compromises cell-cell communication and promotes apoptosis $[24,25]$, and that upregulation of Cx43 restores GJIC and reduces apoptosis [10]. Although the role of $\mathrm{mtC} \times 43$ in regulating mitochondrial dynamics and apoptosis remains unclear, studies suggest that upregulating Cx43 in endothelial cells increases Cx43 level in the mitochondria [15,26,27], which could facilitate preservation of $\mathrm{mtCx} 43$ level, inhibition of cytochrome-c release, thereby preventing apoptosis [28]. Additionally, studies have shown that $\mathrm{mtCx} 43$ level impacts mitochondrial morphology and apoptosis in cardiomyocytes [8] and that $\mathrm{mtC} \times 43$ overexpression reduces cytochrome c release and caspase-3 activation [29]. However, it is unknown whether counteracting HG-induced decrease in mtCx43 level would facilitate preservation of mitochondrial morphology, prevent HG-induced mitochondrial fragmentation and thereby prevent apoptosis.

Presence of $\mathrm{Cx} 43$ in the mitochondria and the subsequent maintenance of $\mathrm{mtC} \times 43$ level play a critical role in regulating cell death [30]. Studies demonstrate that the full-length Cx43 is present in the IMM where it is translocated from the cytosol [17] and that inhibition of $\mathrm{Cx} 43$ translocation to mitochondria and subsequent reduced $\mathrm{mtCx} 43$ level accelerates cell death [16] by reducing cellular respiration [17], promoting mitochondrial energy deprivation and triggering apoptosis [18]. Additionally, evidence suggests that reduced $\mathrm{mtCx} 43$ level results in cytochrome $\mathrm{c}$ release and apoptosis, indicating that maintenance of $\mathrm{mtCx} 43$ level could be useful in preventing apoptosis [14]. However, only limited studies [2] have investigated the effects of HG-induced changes in $\mathrm{mtCx} 43$ level in retinal endothelial cells.

Although $\mathrm{mtCx} 43$ is involved in regulating mitochondrial morphology [10,27,31], its modulatory role in regulating apoptosis in HG conditions is not fully understood. Given the likely link between $\mathrm{mtCx} 43$ level and apoptosis, in this study, we have attempted to counteract HG-induced decrease in $\mathrm{mtC} \times 43$ level by upregulating $\mathrm{mtC} \times 43$ expression and investigate whether plasmid-mediated $\mathrm{Cx} 43$ overexpression is sufficient to maintain $\mathrm{mtC} \times 43$ level and thereby prevent HG-induced mitochondrial fragmentation and apoptosis in RRECs.

\section{Materials and Methods}

\subsection{Cell Culture and Transfection}

Rat retinal endothelial cells derived from rat retinas which tested positive for von Willebrand factor (vWF) using immunofluorescence were used in this study as described previously [32]. RRECs were grown in Dulbecco's Modified Eagle's Medium supplemented with $10 \%$ fetal bovine serum, $100 \mathrm{U} / \mathrm{mL}$ penicillin/streptomycin and (Thermo Fisher Scientific, Waltham, MA, USA). To mimic the effect of hyperglycemia RRECs were grown in HG (30 mM) medium for 7 days. In parallel RRECs grown in HG were exposed to pCDNA-Cx43 plasmid (Addgene, Watertown, MA, USA). Transfection of Cx43 plasmid was performed using Lipofectamine 3000 in Opti-MEM (Thermo Fisher Scientific, Waltham, MA, USA) reagent based on the manufacturer's instructions. DR is a long-term complication of diabetes as such the cell culture model used in this study exposes RRECs to HG (30 mM) for seven days as described [33-35].

\subsection{Western Blot Analysis}

The protein expression of cytosolic $\mathrm{Cx} 43, \mathrm{mtC} \times 43$, cleaved caspase-3, Bax, and cleaved PARP was determined using $20 \mu \mathrm{g}$ of the total proteins which were separated using a 10-12\% SDS-PAGE and transferred onto a PVDF membrane (Millipore, Billerica, MA, USA) using a semidry apparatus (Bio-Rad, Hercules, CA, USA) and blocked with 5\% non-fat dry milk for $1 \mathrm{~h}$ and incubated overnight at $4{ }^{\circ} \mathrm{C}$ with antibodies against $\mathrm{Cx} 43$, Cleaved caspase-3, Bax, and cleaved PARP (catalog numbers 3512S, 9662S, 2774S, 9542S, respectively, at 1:1000 dilution, Cell Signaling Technology, Danvers, MA, USA) antibodies 
in a solution of Tris-buffered saline containing 0.1\% Tween-20 (TTBS) 5\% non-fat dry milk. The following day, the membrane was washed with TTBS and exposed to a secondary antibody solution containing AP-conjugated anti-rabbit IgG (Catalog number 7054 at 1:3000 Cell Signaling, Danvers, MA, USA) or anti-mouse IgG (Catalog number 7054 at 1:3000 Cell Signaling, Danvers, MA, USA) for the appropriate primary antibodies, (Catalog number 7056 at 1:3000 Cell Signaling, Danvers, MA, USA) for $1 \mathrm{~h}$ at room temperature (RT). The membrane was washed with TTBS, and subjected to Immuno-Star chemiluminescent substrate (Bio-Rad, Hercules, CA, USA) and imaged using chemiluminescence imager (Fuji Film LAS-4000, Tokyo, Japan). The amount of protein loaded in the gel lanes was confirmed through Ponceau-S staining after transfer and exposing the stripped membrane to $\beta$-actin antibody (Catalog number sc-47778, at 1:1000, Santa Cruz Biotechnology, Dallas, TX, USA). Protein expression was quantified using densitometric analysis of the chemiluminescent signal at non-saturating exposures and analyzed using ImageJ software [36].

\subsection{Mitochondrial and Cytoplasmic Protein Isolation}

Mitochondrial and cytosolic fraction was isolated from RRECs using Mitochondrial isolation from cultured Cells Kit (Thermo, Rockford, IL, USA). Purity of protein samples from cytosolic and mitochondrial cell fractions was determined by probing for voltagedependent anion channel (VDAC) using antibody against VDAC (Catalog number 4661S, at 1:1000 dilution, Cell Signaling Technology, Danvers, MA, USA).

\subsection{Confocal Imaging of Mitochondrial Fragmentation in Live Cells}

Confocal imaging was performed using a Zeiss LSM-710 Meta microscope (Carl Zeiss, Oberkochen, Germany) using 63X oil immersion in live RRECs. Cells were incubated at $37{ }^{\circ} \mathrm{C}$ in a humidified microscope stage chamber containing $5 \% \mathrm{CO}_{2}$. Mito Tracker Red (Thermo Fisher Scientific, Waltham, MA, USA) was subjected to $543 \mathrm{~nm}$ helium/neon laser excitation and emission was recorded through a bandpass 650 to $710 \mathrm{~nm}$ filter (Zeiss, Thornwood, NY, USA). The mitochondrial images were acquired and analyzed using the ImageJ software (version:1.8.0, NIH, Bethesda, MD, USA). The image was first converted to 8-bit and processed using median filter to isolate and equalize fluorescent pixels and particle analysis option to acquire form factor values (FF; $\left(4 \pi^{*}\right.$ Area/perimeter 2$)$ ) and aspect ratio (AR), which were calculated from lengths of major and minor axis [37,38]. An aspect ratio value of 1 indicated circular mitochondria, and elongated mitochondria displayed increased AR values. FF value of 1 represents a circular and un-branched mitochondrion. The longer and more-branched mitochondria have higher FF values.

\subsection{TUNEL Assay}

TUNEL analysis was performed using ApopTag Fluorescein Direct in Situ Apoptosis Detection Kit (Millipore, Billerica, MA, USA) according to the manufacturer's protocol. RRECs were grown on coverslips for 6 days, fixed with $1 \%$ paraformaldehyde for $10 \mathrm{~min}$ at RT, and permeated for $5 \mathrm{~min}$ at $-20{ }^{\circ} \mathrm{C}$ with a precooled mixture of a 2:1 ratio of ethanol/acetic acid. The cells were then washed $2 \times$ with PBS for 5 min each, slides were incubated with equilibration buffer and subsequently with TdT enzyme in a moist chamber at $37^{\circ} \mathrm{C}$ for $1 \mathrm{~h}$. The cells were again washed with Phosphate buffered saline (PBS) and incubated with anti-digoxigenin peroxidase for $30 \mathrm{~min}$ at RT. Finally, cells were washed with PBS and mounted with reagent (SlowFade; Molecular Probes, Eugene, OR, USA). Images of 10 random fields were captured using a digital fluorescent microscope (Eclipse E600; Nikon Corp., Tokyo, Japan) and recorded for analysis. Merged DAPI and FITC stained cells were counted using the Image J software [36]. 


\subsection{Statistical Analysis}

Statistical analysis was performed using GraphPad Prism software version 9.0 (GraphPad Software, San Diego, CA, USA). All data are expressed as mean \pm standard deviation (SD). Values of the control groups were normalized to $100 \%$, and values from all other groups were expressed as percentages of control. Statistical analysis was performed using the normalized values. Comparisons between groups were performed using one-way ANOVA followed by Bonferroni's post-hoc test. A level of $p<0.05$ was considered statistically significant.

\section{Results}

\subsection{HG-Induced Decreased $m t C x 43$}

WB results indicated a significant decrease in cytosolic $(74 \pm 17 \%$ of $\mathrm{N} ; p<0.05$; Figure 1A) and $\mathrm{mtC} \times 43(72 \pm 10 \%$ of $\mathrm{N} ; p<0.05$; Figure 1B) expression in cells grown in HG compared to those grown in N medium. RRECs grown in HG medium and transfected with Cx43 plasmid showed a significant increase in cytosolic (132 $\pm 17 \%$ of HG; $p<0.05$; Figure $1 \mathrm{~A}$ ) and $\mathrm{mtCx} 43$ expression (181 $\pm 13 \%$ of HG; $p<0.05$; Figure 1B) compared to those grown in HG medium.

A
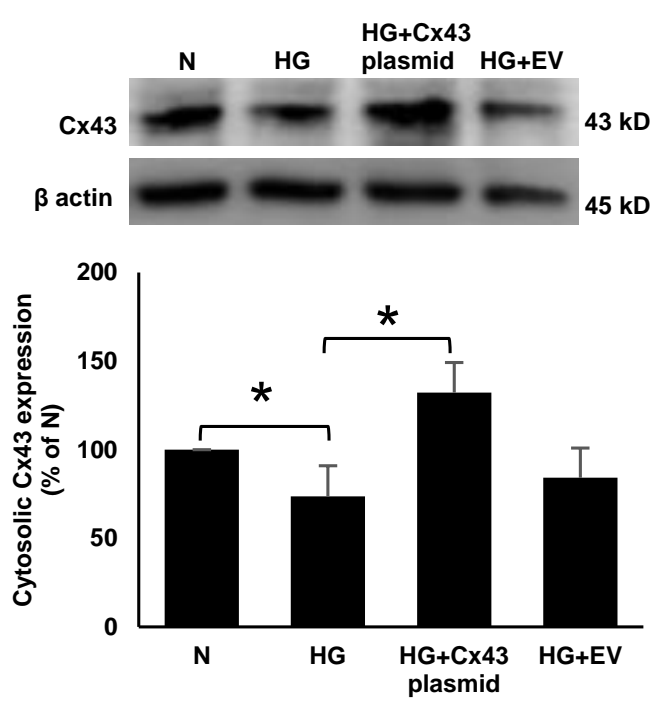

B
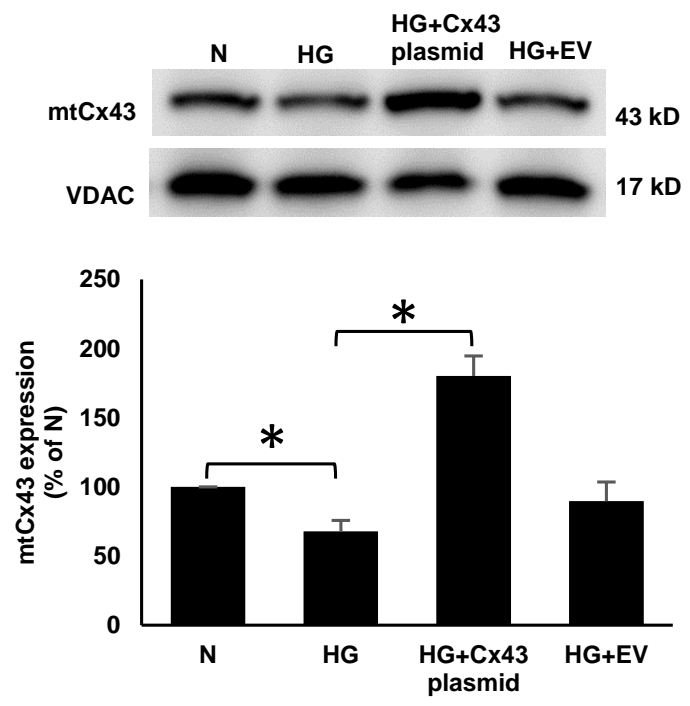

Figure 1. Cx43 plasmid transfection increases mtCx43 level in RRECs. Cytosolic Cx43 expression was significantly decreased in cells grown in HG medium compared to those grown in N medium. (A) Cells grown in HG and transfected with Cx43 plasmid significantly increased cytosolic Cx43 expression compared to those grown in HG medium. Bar graph shows cumulative data obtained from six experiments. (B) Cells grown in HG and transfected with Cx43 plasmid significantly increased mtCx43 level compared to those grown in HG medium. Bar graph shows cumulative data obtained from six experiments. Data are presented as mean $\pm \mathrm{SD}, * p<0.05 ; n=6$.

\subsection{Cx43 Overexpression Reduced Bax, Cleaved Caspase-3 and Cleaved PARP}

RRECs grown in HG medium displayed a significant increase in the expression of Bax $(131 \pm 13 \%$ of $\mathrm{N} ; p<0.05$; Figure 2), cleaved caspase-3 (136 $\pm 15 \%$ of $\mathrm{N} ; p<0.05$; Figure 3), and cleaved PARP (140 $\pm 29 \%$ of $\mathrm{N} ; p<0.05$; Figure 4$)$ compared to those grown in $\mathrm{N}$ medium. On the other hand, cells grown in $\mathrm{HG}$ and transfected with $\mathrm{Cx} 43$ plasmid showed reduced expression of Bax ( $92 \pm 13 \%$ of HG; $p<0.05$; Figure 2$)$, cleaved caspase3 (106 $\pm 12 \%$ of HG; $p<0.05$; Figure 3$)$, and cleaved PARP (99 $\pm 17 \%$ of HG; $p<0.05$; Figure 4) compared to those grown in HG medium. 

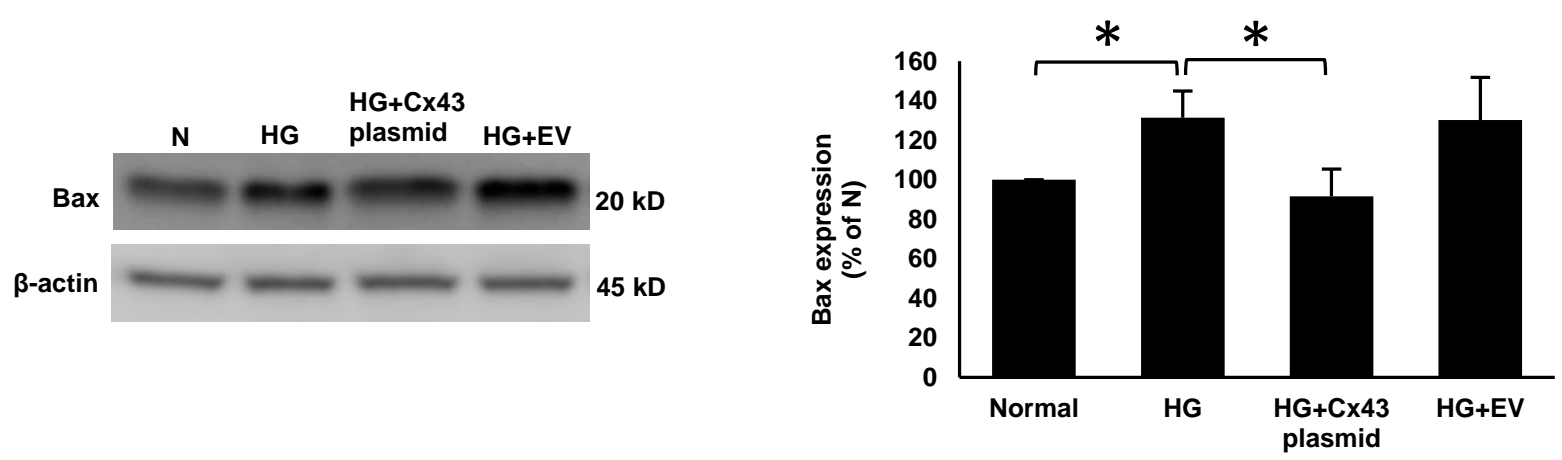

Figure 2. Cx43 upregulation reduces Bax expression. Bax expression was significantly increased in cells grown in HG condition compared to those grown in N medium. In cells grown in HG and transfected with Cx43 plasmid, Bax expression was significantly reduced compared to those grown in HG medium. Bar graph shows cumulative data obtained from six experiments. Data are presented as mean $\pm \mathrm{SD}, * p<0.05 ; n=6$.
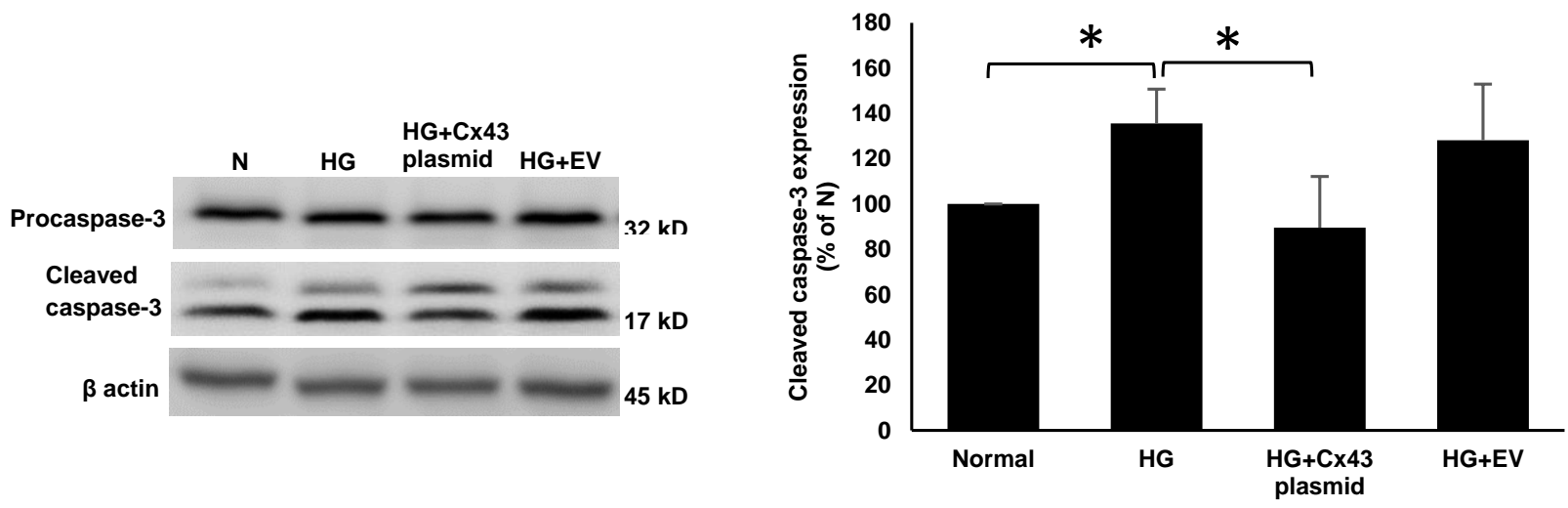

Figure 3. Cx43 overexpression reduces cleaved caspase-3 level. Cleaved caspase-3 level was significantly increased in cells grown in HG compared to those grown in N medium. In cells grown in HG and transfected with Cx43 plasmid, cleaved caspase-3 level was significantly reduced compared to those grown in HG medium. Bar graph shows cumulative data obtained from six experiments. Data are presented as mean $\pm \mathrm{SD},{ }^{*} p<0.05 ; n=6$.
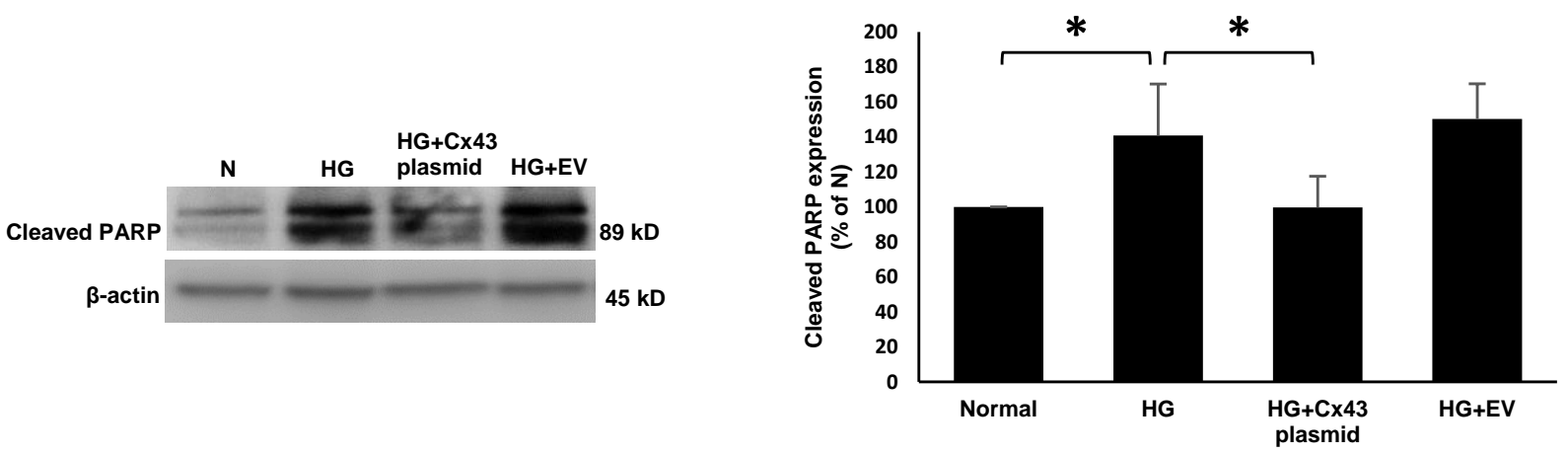

Figure 4. Cx43 overexpression reduces cleaved PARP level. Cleaved PARP level was significantly increased in cells grown in HG compared to those grown in N medium. In cells grown in HG and transfected with Cx43 plasmid, cleaved PARP level was significantly decreased compared to cells grown in HG medium. Bar graph shows cumulative data obtained from six experiments. Data are presented as mean $\pm \mathrm{SD},{ }^{*} p<0.05 ; n=6$. 


\subsection{Cx43 Overexpression Prevented HG-Induced Mitochondrial Fragmentation}

Live confocal microscopy of the cells showed increased mitochondrial fragmentation under $\mathrm{HG}$ condition; a significant decrease in FF and AR was observed in cells grown in HG compared to those grown in $\mathrm{N}$ medium (HG: $\mathrm{FF}=1.58 \pm 0.12 ; p<0.05 ; \mathrm{AR}=1.92 \pm 0.06$; $p<0.05$; Figure 5B; N: $\mathrm{FF}=2.9 \pm 0.47 ; p<0.05 ; \mathrm{AR}=2.45 \pm 1 ; p<0.05$, Figure 5C). The cells grown in $\mathrm{HG}$ and transfected with Cx43 plasmid showed significant increase in FF and AR values compared to the those grown in $\mathrm{HG}(\mathrm{HG}+\mathrm{Cx} 43$ plasmid: $\mathrm{FF}=2.95 \pm 0.47 ; p<0.05$; Figure 5B; $A R=2.51 \pm 0.16 ; p<0.05$, Figure 5 C).

A
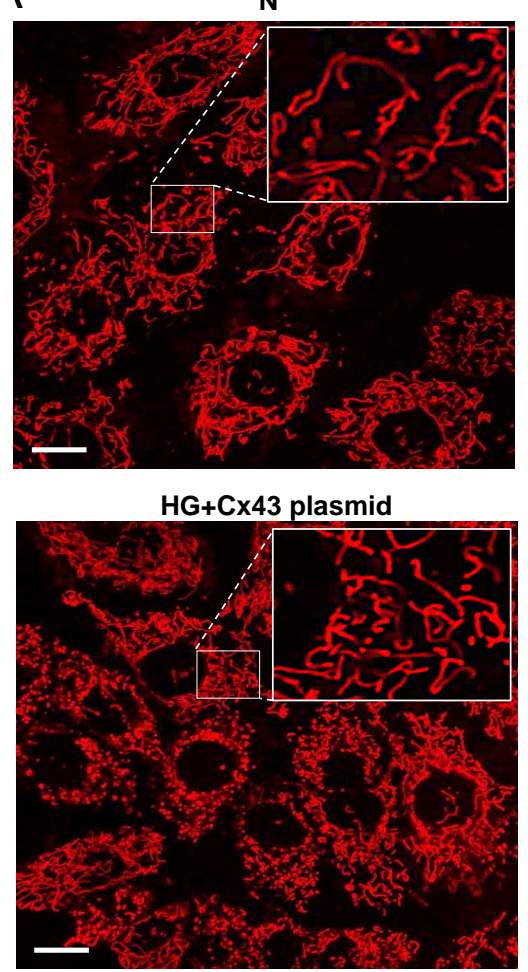

HG

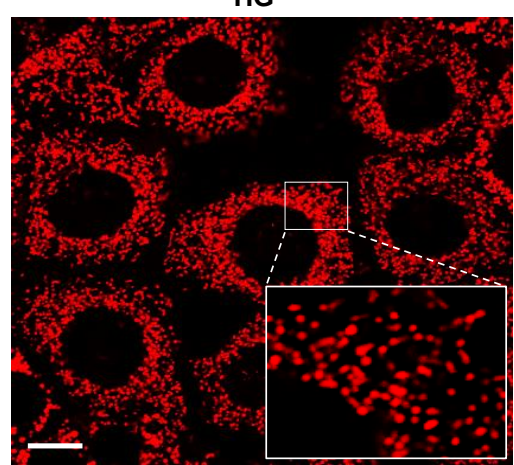

$\mathrm{HG}+\mathrm{EV}$

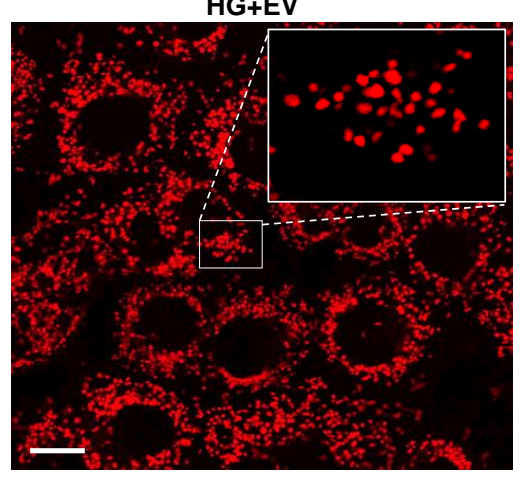

$\mathrm{B}$
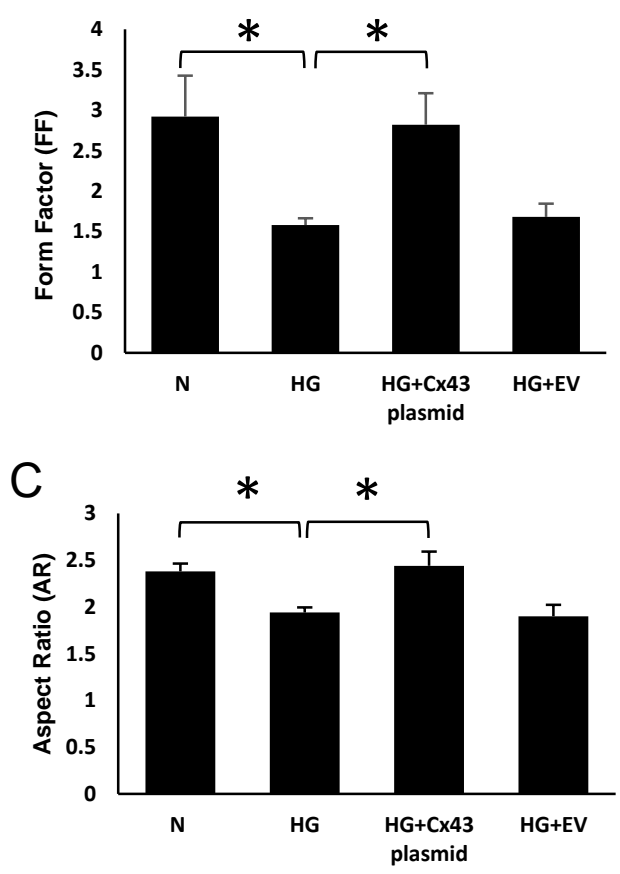

Figure 5. Effect of upregulating mtCx43 level against HG-induced mtCx43 downregulation on mitochondrial fragmentation. Plasmid-mediated Cx43 overexpression improved $\mathrm{mtCx} 43$ level and reduced mitochondrial fragmentation in HG condition. (A) Representative images of mitochondrial networks in RRECs grown in N medium, HG, HG and transfected with Cx43 plasmid or empty vector, as control. Scale bar $=10 \mu \mathrm{m}$. The large inset represents an enlarged view of the corresponding field as indicated by dotted lines in each panel. The graph shows average (B) FF and (C) AR values for mitochondria in RRECs grown in HG medium and transfected with Cx43 plasmid or empty vector. Data are presented as mean \pm SD, $\left({ }^{*} p<0.05 ; n=5\right)$.

\subsection{HG-Induced Apoptosis Is Prevented by $m t C x 43$ Overexpression}

TUNEL assay data showed that the number of TUNEL-positive cells was significantly increased in RRECs grown in HG compared to those grown in N medium ( $254 \pm 3 \%$; TUNELpositive cells compared with TUNEL-positive cells in N; $p<0.05$; Figure 6A,B). However, RRECs grown in HG and transfected with Cx43 plasmid showed a significant reduction in TUNEL positive cells compared to cells grown in HG (107 $\pm 2 \%$ in Cx43 transfected cells versus $254 \pm 3 \%$ TUNEL-positive cells in HG; $p<0.05$; Figure 6A,B), respectively. 
A
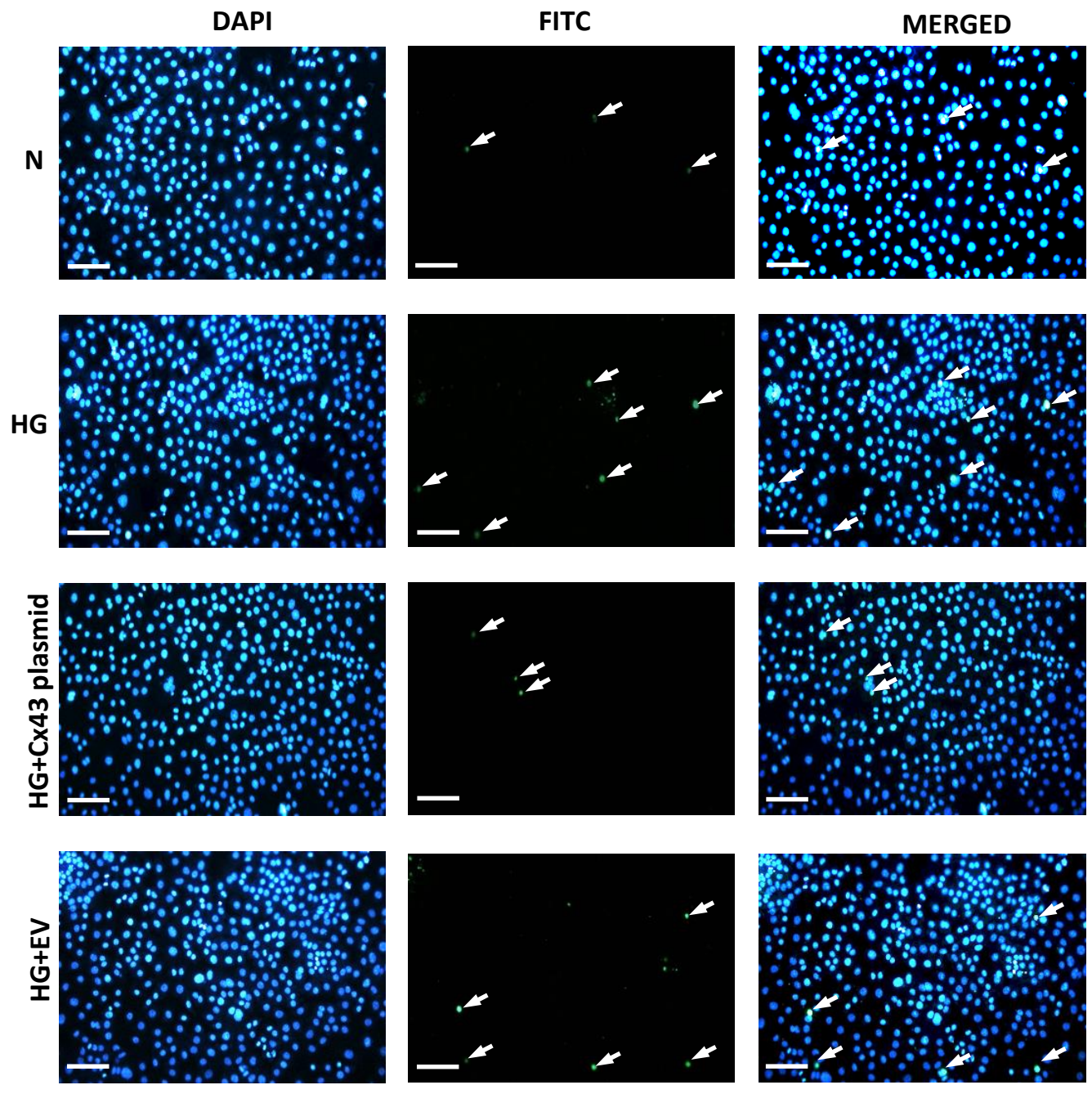

B

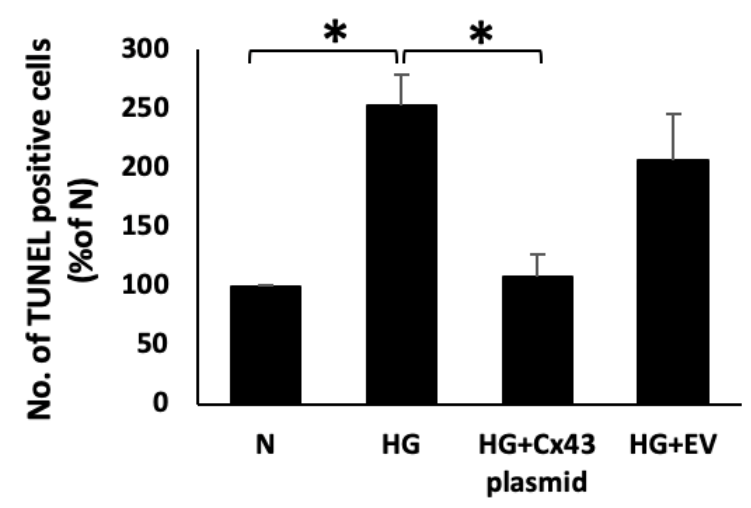

Figure 6. Effect of Cx43 overexpression on apoptosis. (A) Representative photomicrographs show a significant increase in the number of TUNEL positive cells (white arrows) in RRECs grown in HG medium compared to those grown in $\mathrm{N}$ medium. The cells grown in HG medium and transfected with Cx43 plasmid showed reduced TUNEL positive cells (white arrows) compared to those grown in HG medium. Merged panel shows DAPI stained cells superimposed with TUNEL-positive cells. Scale bar $=100 \mu \mathrm{m}$. (B) Bar graph shows cumulative data obtained from five experiments. Data are presented as mean $\pm \mathrm{SD},\left({ }^{*} p<0.05 ; n=5\right)$. 


\section{Discussion}

The current study indicates the beneficial effects of increasing $\mathrm{mtCx} 43$ expression which prevents apoptosis in RRECs grown in HG condition. Here, we observed that plasmid-mediated overexpression of $\mathrm{C} \times 43$ resulted in a significant increase in cytosolic $\mathrm{Cx} 43$ level as expected, and importantly, increased $\mathrm{mtCx} 43$ level as well. Such increase in $\mathrm{mtCx} 43$ level prevented HG-induced mitochondrial fragmentation, reduced Bax overexpression, cleaved caspase-3, and cleaved PARP levels. Findings from this study suggest that $\mathrm{mtC} \times 43$ upregulation prevents HG-induced mitochondrial fragmentation and apoptosis in RRECs.

The role of $\mathrm{mtCx} 43$ in pathophysiological context of diseases including DR is only beginning to be understood. Our previous studies have shown that HG-induced downregulation of $\mathrm{mtCx} 43$ in RRECs compromises mitochondrial morphology, increases mitochondrial fragmentation, and apoptosis via release of cytochrome c [10]. Furthermore, Cx43-deficient mitochondria are known to split into smaller fragments, which is indicative of Cx43 as a critical factor impacting mitochondrial fission [39]. In this study, we observed plasmid-mediated Cx43 upregulation in the cytosol increases $\mathrm{mtCx} 43$ level in RRECs. However, it is unclear how overexpression of $\mathrm{C} \times 43$ in the cytosol results in increased $\mathrm{mtC} \times 43$ levels. Translocation of $\mathrm{Cx} 43$ from cytoplasm to mitochondria is a complex process and likely represents a critical event in regulating $\mathrm{mtC} \times 43$ level and preserving mitochondrial morphology. Decreased Cx43 translocation resulting in lower mtCx43 level could therefore compromise mitochondrial integrity [40]. Currently, it is unknown whether HG compromises $\mathrm{C} \times 43$ translocation to the mitochondria.

Although retinal endothelial cells are well connected to each other via $\mathrm{Cx} 43$-mediated gap junctions, non-canonical functions of $\mathrm{mtC} \times 43$ appear to play a significant role in HGmediated apoptosis, and possibly in the development of retinal vascular lesions in DR. Evidence suggests that $\mathrm{mtC} 43$ plays a critical role in maintaining mitochondrial dynamics and regulating apoptosis [14] [8]. Studies have shown that inhibition of $\mathrm{mtCx} 43$ in brown adipose tissue [40] and rat cardiomyocytes results in reduced mitochondrial integrity, increased cytochrome c release, and increased apoptosis [41,42]. In a chemically-induced model of hypoxia, reduced Cx43 translocation on mitochondria increased mitochondrial ROS production that indicated involvement of $\mathrm{mtC} \times 43$ in the apoptotic process [43]. Importantly a study has shown that genetic depletion of $\mathrm{mtCx} 43$ reverses the protection against ischemia and ROS production [9]. Moreover, reduced Cx43 translocation to mitochondria promotes ROS production [40], which is known to be associated with DR. Future directions to the study would include confirmation of our current findings in an animal model of diabetes and examine whether maintenance of $\mathrm{mtC} \times 43$ prevents apoptosis.

Overall, findings from the current study demonstrate that maintenance of $\mathrm{mtCx} 43$ level plays a critical role in protecting against HG-induced apoptosis in RRECs. This novel approach to regulate and maintain $\mathrm{mtCx} 43$ level could thus be beneficial in counteracting the decrease in $\mathrm{mtCx} 43$ level under HG conditions, preventing mitochondrial fragmentation, and ultimately inhibiting apoptosis associated with the development of DR.

Author Contributions: Conceptualization, S.R.; Methodology, A.S. and S.R.; Formal Analysis, A.S. and S.R.; Investigation, A.S. and S.R.; Resources, S.R.; Data Curation, A.S.; Writing-Original Draft Preparation, A.S. and S.R.; Writing-Review and Editing, A.S. and S.R.; Visualization, A.S. and S.R.; Funding Acquisition, S.R. All authors have read and agreed to the published version of the manuscript.

Funding: This work was supported in part by a NEI NIH grant R01 EY027082 (SR).

Institutional Review Board Statement: Not applicable.

Data Availability Statement: Data presented in the article are available by request to corresponding author, Sayon Roy (sayon@bu.edu).

Acknowledgments: We acknowledge the use of the Cellular Imaging Core facility at Boston University School of Medicine.

Conflicts of Interest: The authors declare no conflict of interest. 


\section{References}

1. Teo, Z.L.; Tham, Y.-C.; Yu, M.; Chee, M.L.; Rim, T.H.; Cheung, N.; Bikbov, M.M.; Wang, Y.X.; Tang, Y.; Lu, Y.; et al. Global Prevalence of Diabetic Retinopathy and Projection of Burden through 2045: Systematic Review and Meta-analysis. Ophthalmology 2021, 128, 1580-1591. [CrossRef]

2. Kilpatrick, E.S.; Rigby, A.S.; Atkin, S. The Diabetes Control and Complications Trial: The gift that keeps giving. Nat. Rev. Endocrinol. 2009, 5, 537-545. [CrossRef]

3. Duh, E.J.; Sun, J.; Stitt, A.W. Diabetic retinopathy: Current understanding, mechanisms, and treatment strategies. JCI Insight 2017, 2, 2. [CrossRef] [PubMed]

4. Gan, J.; Huang, M.; Lan, G.; Liu, L.; Xu, F. High Glucose Induces the Loss of Retinal Pericytes Partly via NLRP3-Caspase-1GSDMD-Mediated Pyroptosis. BioMed Res. Int. 2020, 2020, 4510628. [CrossRef] [PubMed]

5. Grant, Z.L.; Whitehead, L.; Wong, V.H.Y.; He, Z.; Yan, R.Y.; Miles, A.R.; Benest, A.V.; Bates, D.O.; Prahst, C.; Bentley, K.; et al. Blocking endothelial apoptosis revascularizes the retina in a model of ischemic retinopathy. J. Clin. Investig. 2020, 130, 4235-4251. [CrossRef] [PubMed]

6. Mrugacz, M.; Bryl, A.; Zorena, K. Retinal Vascular Endothelial Cell Dysfunction and Neuroretinal Degeneration in Diabetic Patients. J. Clin. Med. 2021, 10, 458. [CrossRef]

7. Volpe, C.M.O.; Villar-Delfino, P.H.; Dos Anjos, P.M.F.; Nogueira-Machado, J.A. Cellular death, reactive oxygen species (ROS) and diabetic complications. Cell Death Dis. 2018, 9, 119. [CrossRef] [PubMed]

8. Goubaeva, F.; Mikami, M.; Giardina, S.; Ding, B.; Abe, J.; Yang, J. Cardiac mitochondrial connexin 43 regulates apoptosis. Biochem. Biophys. Res. Commun. 2007, 352, 97-103. [CrossRef]

9. Martins-Marques, T.; Ribeiro-Rodrigues, T.M.; Almeida, D.; Aasen, T.; Kwak, B.; Girao, H. Biological Functions of Connexin43 Beyond Intercellular Communication. Trends Cell Biol. 2019, 29, 835-847. [CrossRef]

10. Trudeau, K.; Muto, T.; Roy, S. Downregulation of Mitochondrial Connexin 43 by High Glucose Triggers Mitochondrial Shape Change and Cytochrome c Release in Retinal Endothelial Cells. Investig. Opthalmology Vis. Sci. 2012, 53, 6675-6681. [CrossRef] [PubMed]

11. Chinnaiyan, A.M. The Apoptosome: Heart and Soul of the Cell Death Machine. Neoplasia 1999, 1, 5-15. [CrossRef]

12. Elmore, S. Apoptosis: A review of programmed cell death. Toxicol. Pathol. 2007, 35, 495-516. [CrossRef]

13. Wang, X. The expanding role of mitochondria in apoptosis. Genes Dev. 2001, 15, 2922-2933. [PubMed]

14. Green, D.; Kroemer, G. The central executioners of apoptosis: Caspases or mitochondria? Trends Cell Biol. 1998, 8, $267-271$. [CrossRef]

15. Boengler, K.; Dodoni, G.; Rodriguez-Sinovas, A.; Cabestrero, A.; Ruiz-Meana, M.; Gres, P.; Konietzka, I.; Lopez-Iglesias, C.; GarciaDorado, D.; Di Lisa, F. Connexin 43 in cardiomyocyte mitochondria and its increase by ischemic preconditioning. Cardiovasc. Res. 2005, 67, 234-244. [CrossRef] [PubMed]

16. Boengler, K.; Heusch, G.; Schulz, R. Connexin 43 and ischemic preconditioning: Effects of age and disease. Exp. Gerontol. 2006, 41, 485-488. [CrossRef] [PubMed]

17. Rodriguez-Sinovas, A.; Boengler, K.; Cabestrero, A.; Gres, P.; Morente, M.; Ruiz-Meana, M.; Konietzka, I.; Miró, E.; Totzeck, A.; Heusch, G.; et al. Translocation of Connexin 43 to the Inner Mitochondrial Membrane of Cardiomyocytes Through the Heat Shock Protein 90-Dependent TOM Pathway and Its Importance for Cardioprotection. Circ. Res. 2006, 99, 93-101. [CrossRef] [PubMed]

18. Wang, G.-Y.; Bi, Y.-G.; Liu, X.-D.; Zhao, Y.; Han, J.-F.; Wei, M.; Zhang, Q.-Y. Autophagy was involved in the protective effect of metformin on hyperglycemia-induced cardiomyocyte apoptosis and Connexin43 downregulation in H9c2 cells. Int. J. Med. Sci. 2017, 14, 698-704. [CrossRef]

19. Zhang, X.; Chen, X.; Wu, D.; Liu, W.; Wang, J.; Feng, Z.; Cai, G.; Fu, B.; Hong, Q.; Du, J. Downregulation of Connexin 43 Expression by High Glucose Induces Senescence in Glomerular Mesangial Cells. J. Am. Soc. Nephrol. 2006, 17, 1532-1542. [CrossRef]

20. Agullo-Pascual, E.; Delmar, M. The noncanonical functions of Cx43 in the heart. J. Membr. Biol. 2012, 245, 477-482. [CrossRef]

21. Epifantseva, I.; Xiao, S.; Baum, R.E.; Kléber, A.G.; Hong, T.; Shaw, R.M. An Alternatively Translated Connexin 43 Isoform, GJA1-11k, Localizes to the Nucleus and Can Inhibit Cell Cycle Progression. Biomolecules 2020, 10, 473. [CrossRef] [PubMed]

22. Rusiecka, O.M.; Montgomery, J.; Morel, S.; Batista-Almeida, D.; Van Campenhout, R.; Vinken, M.; Girao, H.; Kwak, B.R. Canonical and Non-Canonical Roles of Connexin43 in Cardioprotection. Biomolecules 2020, 10, 1225. [CrossRef] [PubMed]

23. Li, A.-F.; Roy, S. High Glucose-Induced Downregulation of Connexin 43 Expression Promotes Apoptosis in Microvascular Endothelial Cells. Investig. Opthalmology Vis. Sci. 2009, 50, 1400-1407. [CrossRef] [PubMed]

24. Muto, T.; Tien, T.; Kim, D.; Sarthy, V.P.; Roy, S. High Glucose Alters Cx43 Expression and Gap Junction Intercellular Communication in Retinal Müller Cells: Promotes Müller Cell and Pericyte Apoptosis. Investig. Opthalmol. Vis. Sci. 2014, 55, $4327-4337$. [CrossRef]

25. Roy, S.; Kim, D.; Lim, R. Cell-cell communication in diabetic retinopathy. Vis. Res. 2017, 139, 115-122. [CrossRef]

26. Kozoriz, M.G.; Church, J.; Ozog, M.A.; Naus, C.C.; Krebs, C. Temporary Sequestration of Potassium by Mitochondria in Astrocytes. J. Biol. Chem. 2010, 285, 31107-31119. [CrossRef]

27. Ruiz-Meana, M.; Rodríguez-Sinovas, A.; Cabestrero, A.; Boengler, K.; Heusch, G.; Garcia-Dorado, D. Mitochondrial connexin43 as a new player in the pathophysiology of myocardial ischaemia-reperfusion injury. Cardiovasc. Res. 2007, 77, 325-333. [CrossRef]

28. Lu, G.; Jiang, S.; Ashraf, M.; Haider, K.H. Subcellular preconditioning of stem cells: Mito-Cx43 gene targeting is cytoprotective via shift of mitochondrial Bak and Bcl-xL balance. Regen. Med. 2012, 7, 323-334. [CrossRef] 
29. Lu, G.; Haider, H.K.; Porollo, A.; Ashraf, M. Mitochondria-specific transgenic overexpression of connexin-43 simulates preconditioning-induced cytoprotection of stem cells. Cardiovasc. Res. 2010, 88, 277-286. [CrossRef]

30. Ma, J.-W.; Ji, D.-D.; Li, Q.-Q.; Zhang, T.; Luo, L. Inhibition of connexin 43 attenuates oxidative stress and apoptosis in human umbilical vein endothelial cells. BMC Pulm. Med. 2020, 20, 1-10. [CrossRef]

31. Hou, S.; Shen, P.-P.; Zhao, M.-M.; Liu, X.-P.; Xie, H.-Y.; Deng, F.; Feng, J.-C. Mechanism of Mitochondrial Connexin43's Protection of the Neurovascular Unit under Acute Cerebral Ischemia-Reperfusion Injury. Int. J. Mol. Sci. 2016, 17, 679. [CrossRef]

32. Chronopoulos, A.; Trudeau, K.; Roy, S.; Huang, H.; Vinores, S.A.; Roy, S. High Glucose-induced Altered Basement Membrane Composition and Structure Increases Trans-endothelial Permeability: Implications for Diabetic Retinopathy. Curr. Eye Res. 2011, 36, 747-753. [CrossRef] [PubMed]

33. Kim, D.; Lewis, C.S.; Sarthy, V.P.; Roy, S. High-Glucose-Induced Rab20 Upregulation Disrupts Gap Junction Intercellular Communication and Promotes Apoptosis in Retinal Endothelial and Müller Cells: Implications for Diabetic Retinopathy. J. Clin. Med. 2020, 9, 3710. [CrossRef] [PubMed]

34. Kim, D.; Sankaramoorthy, A.; Roy, S. Downregulation of Drp1 and Fis1 Inhibits Mitochondrial Fission and Prevents High Glucose-Induced Apoptosis in Retinal Endothelial Cells. Cells 2020, 9, 1662. [CrossRef] [PubMed]

35. Roy, S.; Sala, R.; Cagliero, E.; Lorenzi, M. Overexpression of fibronectin induced by diabetes or high glucose: Phenomenon with a memory. Proc. Natl. Acad. Sci. USA 1990, 87, 404-408. [CrossRef] [PubMed]

36. Schneider, C.A.; Rasband, W.S.; Eliceiri, K.W. NIH Image to ImageJ: 25 years of image analysis. Nat. Methods 2012, 9, 671-675. [CrossRef]

37. De Vos, K.; Allan, V.; Grierson, A.; Sheetz, M.P. Mitochondrial Function and Actin Regulate Dynamin-Related Protein 1-Dependent Mitochondrial Fission. Curr. Biol. 2005, 15, 678-683. [CrossRef]

38. Koopman, W.J.H.; Verkaart, S.; Visch, H.-J.; van der Westhuizen, F.; Murphy, M.; Heuvel, L.W.P.J.V.D.; Smeitink, J.A.M.; Willems, P.H. Inhibition of complex I of the electron transport chain causes $\mathrm{O}^{-}{ }^{-}$-mediated mitochondrial outgrowth. Am. J. Physiol. Physiol. 2005, 288, C1440-C1450. [CrossRef] [PubMed]

39. Abhishek, K.S.; Karin Golan, P.; Mark, J.; Althoff, B.S.; Ekaterina, P.-K.; Ashley, M.; Wellendorf, B.S.; Fatima, M.B.S.; Mayla, B.; Daniel, G.-N.; et al. Connexin-43 Is a Negative Regulator of Mitochondrial Fission, Mitophagy and Apoptosis of Di-viding Hematopoietic Stem Cells through the Drp1-Pink1 Axis. Blood 2018, 29, 639.

40. Kim, S.-N.; Kwon, H.-J.; Im, S.-W.; Son, Y.-H.; Akindehin, S.; Jung, Y.-S.; Lee, S.J.; Rhyu, I.J.; Kim, I.Y.; Seong, J.-K.; et al. Connexin 43 is required for the maintenance of mitochondrial integrity in brown adipose tissue. Sci. Rep. 2017, 7, 7159. [CrossRef]

41. Pecoraro, M.; Pinto, A.; Popolo, A. Trastuzumab-induced cardiotoxicity and role of mitochondrial connexin43 in the adaptive response. Toxicol. In Vitro 2020, 67, 104926. [CrossRef] [PubMed]

42. Shin, K.-T.; Nie, Z.-W.; Zhou, W.; Zhou, D.; Kim, J.-Y.; Ock, S.A.; Niu, Y.-J.; Cui, X.-S. Connexin 43 Knockdown Induces Mitochondrial Dysfunction and Affects Early Developmental Competence in Porcine Embryos. Microsc. Microanal. 2020, 26, 287-296. [CrossRef] [PubMed]

43. Pecoraro, M.; Pinto, A.; Popolo, A. Inhibition of Connexin 43 translocation on mitochondria accelerates $\mathrm{CoCl}_{2}$-induced apoptotic response in a chemical model of hypoxia. Toxicol. In Vitro 2018, 47, 120-128. [CrossRef] [PubMed] 